\title{
Monitoring the technical condition of autonomous electrical systems with electric drive
}

\author{
Nikolay Korolev $^{1^{*}}$ and Sergey Solovev ${ }^{1}$ \\ ${ }^{1}$ Saint-Petersburg Mining University, 2, 21 Line of Vasilyevsky Island, St. Petersburg, 199106, Russian Federation
}

\begin{abstract}
The article discusses the structure of autonomous electrical systems with an electric drive and an electric energy generation system. An approach is described for assessing the overall efficiency of technological cycle equipment with specification of parameters that must be considered when calculating it. The necessity of taking into account energy efficiency and operability indicators of autonomous electric complexes is substantiated. The effectiveness of the use of autonomous systems decreases throughout the entire life cycle due to wear and tear. As the operability of electromechanical equipment, an indicator of the residual resource is selected. The calculation of the residual resource, with the definition of its boundary values and recommendations for further use. Nominal energy efficiency parameters of autonomous electrotechnical complexes with electric drive deteriorate during operation, which also needs to be taken into account. To simplify the assessment of the operational state of electromechanical equipment, a state diagram is presented that allows you to track the dynamics of degradation of individual nodes. Taking into account the described indicators and means of control, it is possible to increase the efficiency of using autonomous complexes.
\end{abstract}

\section{Introduction}

At the enterprises of the oil and gas industry, technological complexes with multi-motor alternating current electric drives are being used, the electricity of which is supplied from autonomous sources of electricity. A typical example is the technological complexes of enterprises engaged in exploratory drilling, production and trunk transportation of oil and gas. The need for autonomous power supply may be due to various factors. First of all, it is suitable for objects located in remote areas. Recently, due to a decrease in the reliability of external power supply and a constant increase in electricity tariffs, the transfer to autonomous power supply has become a priority in the electric power industry of oil and gas and other industries [1-5].

Autonomous electrotechnical complexes with a multi-motor electric drive can be reflected in an enlarged circuit, which is shown in Fig. 1. The source of electrical energy is a set of $N$ generators $\mathrm{G}_{k}(k=1, N)$ with drive motors $D_{k}(k=1, N)$, their implementation may be in the form of diesel generators, gas turbine units and, in some cases, wind generators. Using switches $S_{1 k}(k=$ $1, N)$ to a common bus with voltage $U_{0}$ and frequency $f_{0}$ the required number of generators may be included. Consumers are divided into two groups, the main power of which is induction motors $M_{j} \quad(j=1, S)$. Voltages $U_{j}(j=1, S)$ and frequencies $f_{j}(j=1, S)$ on the stator windings of these motors must be regulated during the process, so they receive power from static frequency converters $F C_{j}(j=1, S)$. For the second group of consumers, industrial frequency electricity is needed, so they are connected directly to a common AC bus $[1,2$, 6-8].

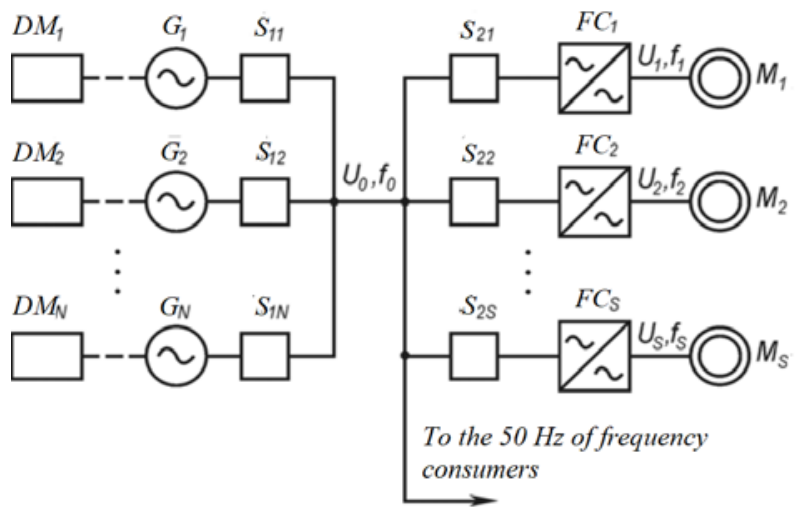

Fig. 1. A generalized scheme of an autonomous electrical complex with a group of electric drives.

The effectiveness of the use of such complexes will depend on many factors and, accordingly, to assess it, an integrated approach is needed that would take into account:

1. Energy efficiency of both generation and technological electric drives;

2. The performance of individual components and the entire autonomous electrical complex as a whole;

3 The degree and uniformity of loading of the electrical complex.

\footnotetext{
* Corresponding author: korolev_na_spmi@mail.ru
} 


\section{Methods}

It was used the world-famous OEE indicator - Overall Equipment Effectiveness, used to measure the overall effectiveness of equipment. The $O E E$ indicator demonstrates that using a simple calculation and analysis algorithm, you can get an answer to the most important question for the head of the enterprise - how to quickly and significantly increase output without introducing additional capacities. OEE exposes the "black box" of losses and allows you to catch the problem areas of production.

According to the definition [9-12], the OEE indicator takes into account three factors:

1. A - Availability, takes into account losses associated with equipment downtime (Down Time Loss). Availability is the ratio of Actual hours worked to Planned Product Release Time;

2. $P$-Performance, takes into account losses associated with a decrease in production speed (Speed Loss). It is the ratio of the number of manufactured products to the time of work multiplied by the rate of production per hour;

3. Q -Quality, takes into account losses associated with poor product quality (Quality Loss). $Q$ is the ratio of the quantity of quality products to all manufactured products.

The resulting expression for the calculation OEE:

$$
O E E=A \cdot P \cdot Q
$$

In international practice, it is generally accepted that OEE is less than $65 \%$, satisfactory - from $65 \%$ to $75 \%$, good - more than $75 \%$ (world industrial leaders have values of $80-85 \%$ ) [9].

OEE is a common indicator for the effective management of the technological cycle, but at the same time it does not allow a qualitative assessment of technical indicators. To supplement information on the overall efficiency of the autonomous complex, additional parameters are required.

Indicators for measuring energy generating device is a power factor $K_{M 1}$ and power factor of electric drives $K_{M 2}$ :

$$
K_{M i}=K_{I} \cdot K_{U} \cdot \cos \varphi
$$

Weighted average power factor $K_{M . a v}$ possible to determine how:

$$
K_{M . a v}=\sqrt{\sum K_{M i}^{2}} / N
$$

where $K_{I}, K_{U}$ - current and voltage non-sinusoidality coefficient; $\cos \varphi$ - cosine of phi; $N$ - the number observed by the electric drive as part of an autonomous complex.

A comprehensive performance indicator for an electric drive will be its residual life $\delta$.

Such indicator depends on values mentioned above and is complicated to determine, as the system can contain vast number of elements (generators, converters, etc.) In this case the emergence of powerful analytical tools should be introduced. It allows operating the accumulated data in a mode close to real time, opens up new possibilities in the area of maintenance and repair systems, and also controlling the using of equipment. In this case, each unit of electromechanical equipment is endowed with "intelligence" without the need for a unified intelligent automation system.

The proposed approach to solving problems of increasing the accuracy and quality of the assessment of the state and residual life of electromechanical equipment is based on the analysis of data of systems for recording the quality of electrical energy, operating environment, vibration and electrical characteristics with using an artificial neural network [13-15].

The determination of the probability of no-failure operation of electric motor under the condition of the retrospective database is based on the algorithm for predicting the probability of trouble-free operation of electric motor and on the work of ANN (the multilayer perceptron), that was described in the articles [16-19]).

After determining the probability of failure and forming the matrix of the probabilities of defects by electric and vibration characteristics with a relative error of less than $5 \%$, the estimate of the electromechanical equipment residual life, based on work of ANN, is made:

$$
\begin{aligned}
& \delta=K_{1} \cdot P_{i h}^{\text {pred.ANN }}(h)+K_{2} \cdot P_{i m}^{\text {pred.ANN }}(m)+ \\
& K_{3} \cdot P_{i h}^{\text {pred.ANN }}(h)+K_{4} \cdot P_{i m}^{\text {pred.ANN }}(m)= \\
& =K_{1} \cdot F\left(\sum_{i=1}^{17}\left(\Delta w_{i j} \cdot x_{i j}-\Delta \theta_{j}\right)+\right. \\
& +K_{2} \cdot F\left(\sum_{i=1}^{17}\left(\Delta w_{i j} \cdot x_{i j}-\Delta \theta_{j}\right)+\right. \\
& +K_{3} \cdot F\left(\sum_{i=1}^{21}\left(\Delta w_{i j} \cdot x_{i j}-\Delta \theta_{j}\right)+\right. \\
& +K_{4} \cdot F\left(\sum_{i=1}^{21}\left(\Delta w_{i j} \cdot x_{i j}-\Delta \theta_{j}\right)\right.
\end{aligned}
$$

$K_{1}$ is a coefficient that takes into account the states of the boundaries of the estimation of vibration parameters taking into account the detected defects at time $\mathrm{t}$ and depending on the normal, pre-crisis and crisis states;

$K_{2}$ is a coefficient that takes into account the states of the boundaries of the estimation of electrical parameters taking into account the onset (detection) of defects at time $t$ and depending on the normal, pre-crisis and crisis conditions;

$K_{3}$ is a coefficient that takes into account the boundaries of the assessment of vibration parameters, taking into account the measured parameters and factors affecting the compilation of the residual resource forecast, at time $\mathrm{t}$ and depending on the normal, precrisis and crisis conditions;

$K_{4}$ is a coefficient that takes into account the states of the boundaries of the estimation of electrical parameters, taking into account the measured parameters and factors influencing the compilation of the residual resource forecast, at time $\mathrm{t}$ and depending on the normal, precrisis and crisis conditions; 
Table 1. Levels of an estimation of a residual life of the AC motor.

\begin{tabular}{|c|c|c|}
\hline $\begin{array}{c}\text { Residual life } \\
\text { indicator } \boldsymbol{\delta}\end{array}$ & Description of technical state & Release to service \\
\hline $1<\delta \leq 0.9$ & "Reference" state, there is no effect on performance & Allow \\
\hline $0.9<\delta \leq 0.8$ & "Normal" state, the impact on performance is not significant \\
\hline $0.8<\delta \leq 0.6$ & $\begin{array}{r}\text { "Pre-crisis" state, the periodical comprehensive diagnosis and } \\
\text { the reducing the load on the unit are recomended }\end{array}$ & $\begin{array}{c}\text { Allow after } \\
\text { comprehensive diagnosis }\end{array}$ \\
\hline $0.6<\delta \leq 0$ & $\begin{array}{r}\text { "Crisis" state, it is the high probability of failure equipment, the } \\
\text { maintenance and repair work are required }\end{array}$ & Prohibit \\
\hline
\end{tabular}

$P_{i h}{ }^{\text {pred.ANN }}(h), P_{i m}{ }^{\text {pred.ANN }}(h)$ are predicted values of the probability estimate based on vibration and electrical parameters and ANN.

$$
\Delta w_{i j}=\varepsilon\left(d_{j}^{s}-y_{j}^{s}\right) \cdot x_{i j}, \Delta \theta_{j}=-\varepsilon\left(d_{j}^{s}-y_{j}^{s}\right)
$$

$\Delta w_{i j}, \Delta \theta_{j}$ - correction for weight coefficients and threshold levels, taking into account the calculated yield and comparison of the obtained output vector $y^{s}{ }_{j}$ with the reference $d_{j}^{s}$;

$\varepsilon$ - rate of training ANN.

\section{Results}

The results of the system work for diagnosing the technical condition and estimating the residual life of the electromechanical equipment are diagnostic graphs of the technical state probabilities (Fig. 2-4).

Based on the results of processing parameters on the laboratory bench, the normal state of the unit was determined for all characteristics (Fig. 2). The calculated value of the residual life, obtained by ANN and electrical, vibration and indirect parameters, and also the detected defects, was estimated in accordance with the limits, presented in Table 1.

The artificial weakening of the mechanical fastening of the equipment led to the appearance of static and dynamic eccentricity and the emergence of these parameters in the pre-crisis zone, as a result, the estimation of the remaining resource corresponds to the level of the pre-crisis state (Table 1). A number of other parameters also went out the boundary of the normal probabilistic technical state.

In addition to the weakening of the mechanical fastening, an interturn closure, an asymmetry of the supply voltage and a bearing damage were artificially created. The presence of both electrical and mechanical inherent damage of the unit led to a violation of electromagnetic symmetry, as a result static and dynamic eccentricities began to rapidly move to the critical state zone, and as a result of significant vibrations, mechanical attenuation increased. Estimation of the residual resource after a long operation of the machine with artificially created defects corresponds to the level of the crisis state. The equipment is subject to withdrawal of the electric motor for repair. In this case, this method gives an accurate knowledge of what part of the machine we need to pay attention to in maintenance and repair work.

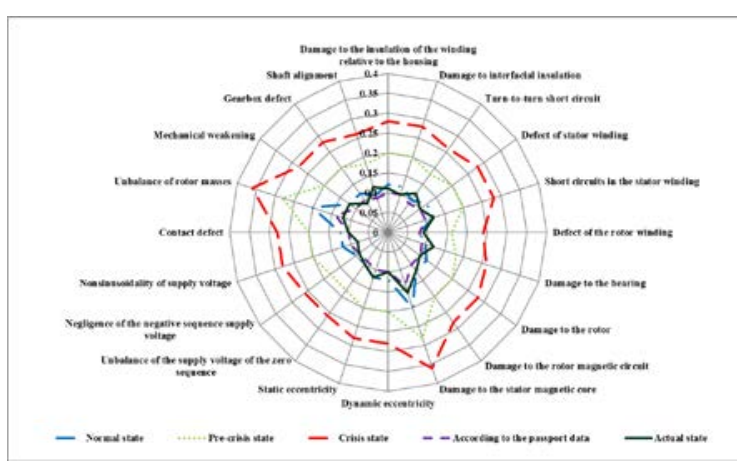

Fig. 2. The diagram of the probabilistic technical state: the normal state.

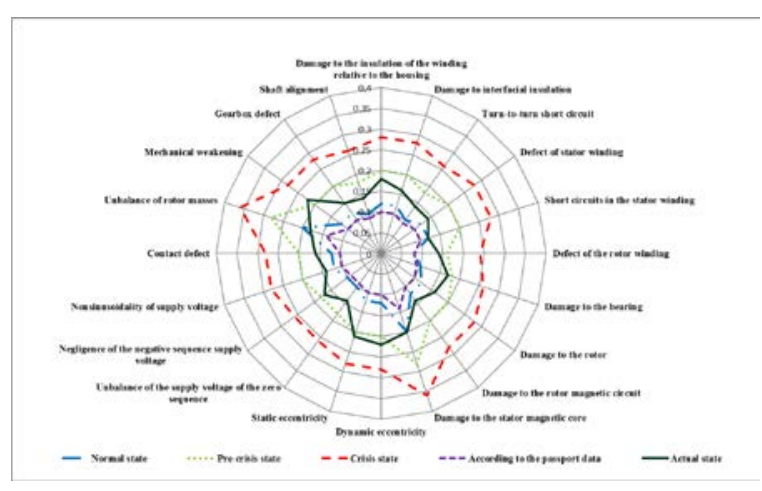

Fig. 3. The diagram of the probabilistic technical state: the precrisis state.

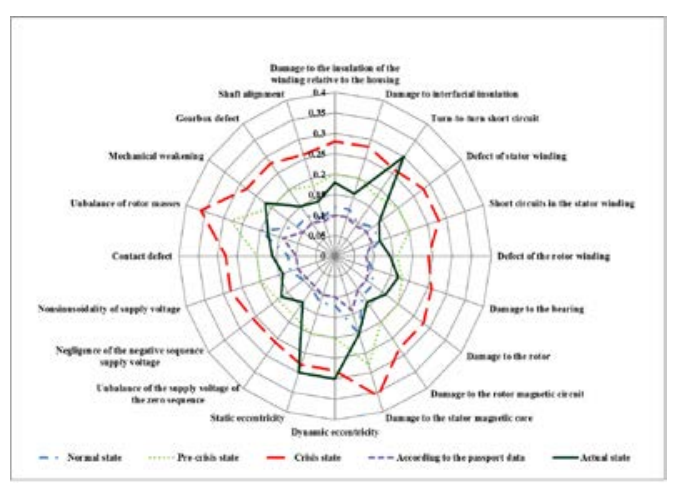

Fig. 4. The diagram of the probabilistic technical state: the crisis state. 


\section{Conclusions}

The result of an analysis of the operation of an autonomous electrical complex with an electric drive is an assessment of its effectiveness, taking into account the predicted value of the residual life:

1. Assess not only the actual OEE efficiency ratio, but also evaluate its change in the projected area;

2. Draw up an effective plan for technical inspections and repairs;

3. To exclude modes of operation with a reduced power factor, both the generator and the electric drive with a frequency converter;

4. Perform proactive control to ensure the required speed and torque in accordance with the technological mode.

\section{References}

1. Belsky A.A., Dobush V.S. Autonomous Electrothermal Facility for Oil Recovery Intensification Fed by Wind Driven Power Unit. IOP Conference Series: Earth and Environmental Science. 2017, Vol. 87, Issue 3, 03 (2006)

2. Belsky A.A., Dobush V.S. Oil well electrical heating facility utilizing heating cable powered by autonomous wind-driven power unit (Dynamics of Systems, Mechanisms and Machines 2016)

3. Belsky A.A., Dobush V.S. Analysis of UPS impact on power quality at point of common coupling of consumers (International Conference on Mechanical Engineering, Automation and Control Systems 2015)

4. Belsky A.A., Dobush V.S. Analysis of UPS impact on voltage THD at point of common coupling. International Journal of Applied Engineering Research. 2016) Vol. 11, Issue 7, pp. 4995-4998

5. Frolov, V.Ya., Ivanov, D.V. Calculation of a plasma composition and its thermophysical properties in cases of maintaining or quenching of electric arcs, J. Phys.: Conf. Ser. 1058012040 (2018) pp. 1-6

6. Frolov V., Kvashnin A., Murashov I. (2018). Nonstationary mathematical model of a magnetic arc blast system. Proc. of EIConRus 2018, pp. 622-625, 2018

7. Chusov A., Podporkin G.V., Pinchuk M., Ivanov D., Murashov, I., Frolov, V. Development of a physical 2-D model for arc quenching chamber of lightning protection multichamber systems, proc of 33rd International Conference on Lightning Protection (ICLP), pp. 1-9, 2016

8. Toropchin A., Frolov V., Pipa A.V., Kozakov R., Uhrlandt D. Influence of the arc plasma parameters on the weld pool profile in TIG welding, J. Phys.: Conf. Ser, 550 012004, 2014, pp. 1 -11

9. Hansen, Robert C. Overall Equipment Effectiveness: a powerful production maintenance tool for increased profits. Industrial Press, 2001. ISBN 0-8311-3138-1

10. Zhukovskiy $\mathrm{Y}$ and Koteleva N (2017) IOP Conference Series: Materials Science and Engineering 177(1) 012014
11. Matyukhin P.V., Markov V.O., Rabunets P.V. (Overall Industrial Equipment Effectiveness European Journal of Natural History. 2010) № 5. C. 53.

12. Abramova I.G., Abramov D.A. Overall equipment effectiveness implementation criteria IOP Conference Series: Materials Science and Engineering, 30 012052, (2018)

13. Martins Cunha C C and CARDOSO FILHO B J IEMDC 2003 - IEEE International Electric Machines and Drives Conference (2003) 703-708

14. Thomson W.T., \& Fenger M. Current signature analysis to detect induction motor faults. IEEE Ind. Appl. Mag. 2001 7(4) 26-34

15. Sang Bin Lee, Tae-June Kang, Heedong Kim, Taesik Kong, Chaewoong Lim, Case studies of stator winding turn insulation failures in medium voltage motors," 2017 Annual Pulp, Paper And Forest Industries Technical Conference (PPFIC), Tacoma, WA, 2017, pp. 1-8

16. Şimşir, Mehmet et al. Real-Time Monitoring and Fault Diagnosis of a Low Power Hub Motor Using Feedforward Neural Network, Computational intelligence and neuroscience vol. 2016 (2016)

17. Malarev V I, Kopteva A V and Nogtev R A 2018 Electric drive simulation for drilling machine spinner IOP C. Ser.: Earth Env. 194(5) 052012

18. C. Hsiao, M. Liu Failure mode analysis of induction motor model, proc. of 2017 International Conference on Applied System Innovation (ICASI), Sapporo, pp. 25-28, (2017)

19. J. A. Antonino-Daviu, A. Quijano-López, M. Rubbiolo, V. Climente-Alarcon, Advanced Analysis of Motor Currents for the Diagnosis of the Rotor Condition in Electric Motors Operating in Mining Facilities, in IEEE Transactions on Industry Applications, Vol. 54, no. 4, pp. 3934-3942, (2018) 